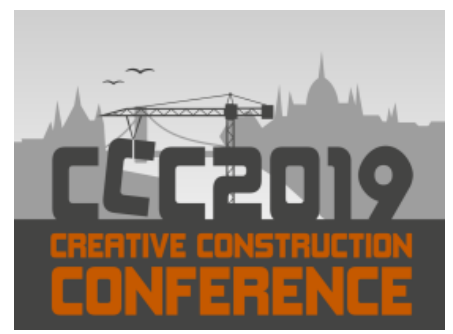

Available online at 2019.creative-construction-conference.com/proceedings/

CCC 2019

Proceedings of the Creative Construction Conference (2019) 059

Edited by: Miroslaw J. Skibniewski \& Miklos Hajdu

https://doi.org/10.3311/CCC2019-059

Creative Construction Conference 2019, CCC 2019, 29 June - 2 July 2019, Budapest, Hungary

\title{
Skilled Electrical Labor Issues in the Mid-Western United States
}

\author{
Evan Taylor ${ }^{\mathrm{a}}$ and Anoop Sattineni ${ }^{\mathrm{a}}$ \\ ${ }^{a}$ Auburn University, 118 M. Miller Gorrie Center, Auburn, AL, 36849, USA
}

\begin{abstract}
This research report aims to determine the status of the electrical workforce in the Midwest and identifying ways electrical contractors are overcoming challenges experienced with electrical skilled labor. The objectives of the report include evaluating contractors' perspective on the electrical skilled workforce in the Midwest region, complete a literature review on this topic which includes identifying the current status, causes of the labor shortage in the industry, and potential solutions to the skilled labor shortage in the United States, and determine the methods which contractors are utilizing to become less dependent on the quality/quantity of skilled labor available. The strategy utilized to complete these objectives include conducting a literature review to determine the current state of knowledge on this topic, holding pilot interviews to obtain both qualitative and quantitative data on the status of the skilled electrical workforce, and generating a questionnaire to be provided to a larger population to enhance the level of confidence in the previous findings. The literate review revealed a disconnect between the root cause of the skilled labor shortage and the steps the industry is taking to alleviate it. The construction industry must overcome challenges imposed by industry image and a push for all young adults to attend college. Attracting a younger and more diverse workforce is a primary solution to overcoming a skilled labor shortage. The pilot interviews on the status of the electrical workforce uncovered six main themes affecting the current workforce which includes demand, quality, age, materials, technology, and alternative labor. The questionnaire, developed from these six main themes, verified the need for additional research on this topic as many of the responses received were split 50-50 on these themes. Contractors are concerned about the number of skilled workers due to retire and it's not since they will need to be replaced, but rather the amount of skill and experience which is being lost. Younger skilled labor is perceived to be incompetent in working hard and completing quality work.
\end{abstract}

(C) 2019 The Authors. Published by Budapest University of Technology and Economics \& Diamond Congress Ltd.

Peer-review under responsibility of the scientific committee of the Creative Construction Conference 2019.

Keywords: Electrical, Skilled Labor, Labor Shotage, Labor Demand;

\section{Introduction}

Exactly how severe is the skilled labor shortage in the United States. In a survey conducted by the AGC of America, it is the biggest concern of all construction companies and has been growing over the past few years [1]. How did the United States end up with such a shortfall of skilled labor? One of the primary causes of the labor shortage is an issue that plagues the construction industry itself and that is inconsistencies. The construction industry is very volatile and experiences extreme variations in the need for skilled labor which naturally leads to shortages when the economy and industry are doing well. During the last recession, the construction industry lost millions of skilled workers and is finally seeing the employment numbers reach their highest mark since 2008 [2]. Based on data obtained in April, the construction industry currently employs nearly 4.2 million workers, and this does not include workers who build single-

*Corresponding author: Anoop Sattineni email: sattian@auburn.edu 
Anoop Sattineni / Proceedings of the Creative Construction Conference (2019) 059

https://doi.org/10.3311/CCC2019-059

family homes. This isn't too far off from the number of workers the construction industry employed when it peaked at 4.4 million in November of 2008 [2].

While we are nearing the highest workforce ever employed by the construction industry, forecasts are showing it still isn't enough. The Associated Builders and Contractors estimates at least 500,000 more construction workers are needed to fill the gap. This number would increase by an additional 600,000 if the federal government released more than $\$ 1$ trillion in infrastructure repair and replacement. To cope with the shortage, many contractors are forming joint ventures and adding staff whose sole responsibility is to recruit new workers from high schools, military bases, and trade schools. The shortage has also created a backlog of work for companies such as Wilmer Electric Services who currently have 18 months' worth of work on the books [2].

Every construction company must have enough supply of quality skilled labor to be successful. The diminished pool of skilled labor means contractors must take what they can get and have little options for picking the best individuals for the job. The lack of quality labor requires the contractor to hold firmly onto the ones they have by offering additional pay or incentives to remain with the company. The overall success of the construction industry lies with their ability to recruit and retain skilled individuals in various construction crafts. Determining the root cause and bringing awareness of the growing labor shortage is the beginning of the rectification process.

\section{Literature Review}

This section will cover a critical analysis of previously publicized data and information related to the research topic. The literature review is broken into three sections which are relevant to the research aim. The three topics researched include the current state of skilled labor shortage in construction, causes of the skilled labor shortage, and proposed solutions to the skilled labor shortage. Each section will include references from various sources citing similar statistics and rationale for topics related to the labor shortage.

\subsection{Current State of Skilled Labor Shortage}

To determine a plausible solution to the skilled labor shortage we first must investigate the current status of the issue at hand. The construction labor shortage is well known and has been verified by surveys conducted by the AGC and statistics obtained from the Department of labor. There have also been numerous reports covering this topic with some dating back to the 1980 's. The literature review of this topic has quickly show that this is not a new issue and it has plagued the construction industry for many years. The 2017 Outlook Survey completed by the AGC provides great insight in how the construction industry views the current labor shortage. From this survey, 66\% of respondents have had difficulty filling skilled labor positions and $75 \%$ of the respondents believe it will only get worse [2]. This does not bode well for an industry which is anticipating continual growth.

Like all other construction crafts, the electrician craft has not been immune to the labor shortage. Statistics are showing the situation is possibly getting worse. From the US Department of labor, there were 628,800 electricians employed in 2014 and in 2016 there were 607,120 [3]. The loss of more than 20,000 workers over the past two years laminates the issue of finding these skilled workers as shown in the surveys from the AGC. To make matters worse, the Department of Labor is predicting a 14\% increase in employment of electricians between 2014 and 2024. That would place the demand at 714,700 meaning the construction industry must work to add over 100,000 electrician positions in the next eight years. This will be a daunting task as the average age of construction workers is currently sitting at 43 years [4].

Progress has been made in the apprentice program as more than 206,000 individuals entered in FY 16. Of the 505,371 active apprentices, the construction industry employs the most at 144,583. The electrician craft currently has 41,489 active electricians which is just over 4,000 more than the craft had in FY 15 [5]. An increase in apprentices is a good sign, but more growth will be needed to keep up with the current demand. 
Anoop Sattineni / Proceedings of the Creative Construction Conference (2019) 059 https://doi.org/10.3311/CCC2019-059

\subsection{Causes of Skilled Labor Shortage}

There are many causes that have led to the current skilled labor shortage being experienced by the construction industry. Cataldo [6], states the reasons for the construction labor shortage includes an aging workforce, lack of diversity within the industry, and the industry is simply not attractive to a younger generation. These are just a few reasons which have been discovered during the literature review and each potential cause will be separately identified and analysed. Statistics show the average age of the construction worker is slowly increasing. In 2013, the average age was 42 and in 2015 the average age was listed as 43 . While this may seem like a minor increase, the data behind it shows a much more dramatic consequence of having an aging workforce. In Florida, 29\% of the construction workers are between $45-54$ while another $21 \%$ are 55 years are older [7]. With an average of $21 \%$ of workers due to retire in the next 7 and an anticipated employment growth of $10 \%$ for the construction industry, the problem at hand really begins to magnify [4]. When comparing to other industries, the construction industry has a significantly higher percentage of workers over the age of 45 . The actual percentage is 53 while other industries are at 44 percent [6].

Another potential cause for the labor shortage is the image the construction industry has with a younger generation. The NAHB launched a poll and received just over 2,000 responses from individuals between 18 and 25. Of these respondents, only $3 \%$ wanted to enter the construction industry as an occupation. The top three desired fields include medical, business, and IT. The top four reasons respondents gave include, wanting a less physically demanding job, construction work is difficult, want an office job, and want to open my own business [9]. A report covering the demographics of the labor shortage lists "an inability to attract new talent" as a long-term reason for the shortage [8]. One which will have a profound affect in the future as the demand for construction labor continues to grow. The push for the younger generation to attend college and not trade schools has weekend the industry's ability to attract young talented workers to its workforce. Sullivan et al [7], report that $65 \%$ of high school students in the state of Florida plan on attending college after completing high school. This leaves only a small percentage who may want to join the construction industry and many of which may lack the skills required to be successful. Lack of exposure is a primary reason why many students are no longer looking to the construction industry as a career. Students where once exposed to the industry through shop classes which have mostly been removed high school programs and advisors are not promoting the industry as a potential career option [7]. With the industry struggling to appeal to the younger generation the shortage will only continue to grow as the potential skilled workforce takes positions in other industry's which are more appealing.

A secondary issue with the construction industry's image is its instability. Prior to the great recession, there were 691,900 construction jobs in 2006 and in 2016, even with the economy improving, there were only 457,300 construction jobs which represents a 34\% percent decrease [7]. The significant drop off in the construction labor force and its gradual ascension during this time is shown in Figure 1. During this recession, several workers were dislocated from the industry and never returned or plan on returning as they have found positions in other industries [6].

One of the keys to having a successful industry is diversification and the construction industry simply does not have it. A few reports have focused on the demographics side of the shortage and while the results are not necessarily surprising, they do show a significant lack of diversification within the industry. The workforce is primarily made up of white males with the white race representing $66 \%$ of labor force in 2010 . The other major races include Latinos at $15 \%$, African American at $12 \%$ and Asians at 5\%. It is anticipated by 2050, the percentages for Whites and Latinos will make up $45 \%$ and $30 \%$ of the labor workforce respectively. The projection shows no change for African Americans and only a slight increase to $8 \%$ for Asians [6]. Immigrant workers also make up a good portion of the construction industry's labor. Across the United States, immigrant workers make up approximately $23 \%$ of all construction labor. This is a considerable amount of the labor force which can be drastically affected by ever changing immigration laws. Based on data obtained from NAHB Economics, only $14.1 \%$ of all electricians are immigrant workers. Further analysis shows that lack of education is a primary reason for immigrant workers not joining the electrician craft [7]. 
Anoop Sattineni / Proceedings of the Creative Construction Conference (2019) 059 https://doi.org/10.3311/CCC2019-059

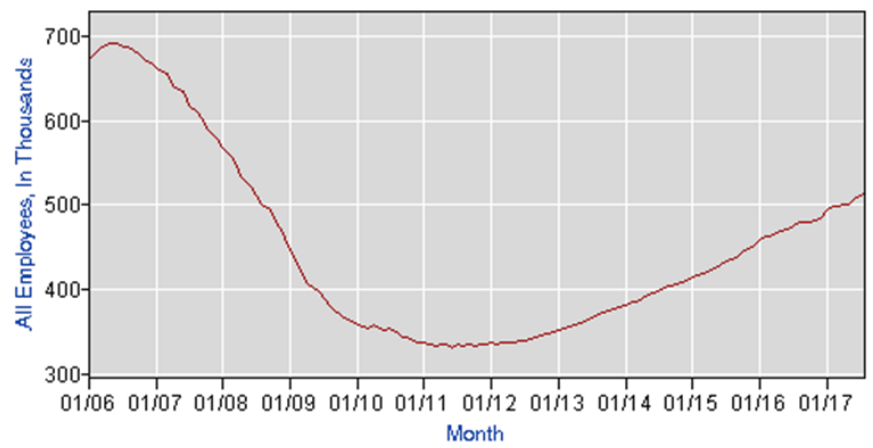

Fig. 1: Construction Industry Labor [3]

Another factor affecting the diversification of the construction industry is the minute percentage which is made up of women. Of all the construction labor force, women only made up 9.1\% in 2016 according to the Bureau of Labor Statistics. Sullivan et al [7], note there are three main causes to the lack of participation from women which include knowledge of the necessary skill, a perception of the industry which is unrealistic, and the challenge of performing work which is dominated by males. This is yet another representation of the need for the construction industry to pursue workers outside its typical demographics to fulfil the current demand for skilled labor.

\subsection{Proposed Solutions to the Skilled Labor Shortage}

To fill the labor gap, the industry should be focused on two areas. The first area which the industry should focus is in attracting new individuals to the workforce and the second would be to work to retain the individuals that already make up the workforce. The following sections will identify the methods currently employed by the industry and what factors attracted and retain the current workforce.

A few of the possible solutions to help bridge the gap include reforming government policies for the use of funds tied to training and education. In a report entitled "An Agenda to Rebuild Our Infrastructure \& Our Craft Workforce", the AGC of America listed the following ways to rebuild the construction workforce. The first item the AGC referred to is the Carl D. Perkins Career \& Technical Education Act, of which they call for more flexibility for the states to choose where the funds should be best utilized given the labor needs at the time. They also call for changes to the Pell Grant which would allow it to be used by individuals attending career or technical programs. The report suggest that students should be able to participate in technical programs while still in high school and receive credit towards their diploma and be able to enter the workforce trained and ready upon graduation. Other items listed in the report include allowing veterans to get the same assistance for apprentice programs as they would for educational programs and reforming immigration laws to allow for undocumented immigrants who have been working in the United States for years to be converted to legal status. The AGC developed this report and sent it to the new administration in January of 2017 [10]. While many of these changes will help add more individuals to the workforce, it doesn't appear to focus on the all the major causes for this labor shortage. One item which was left out of the report was diversification. It appears the report is focused on doing more of the same and appealing to the groups which currently make up a majority of the workforce instead of developing new methods to reach out to groups who are underrepresented in the workforce.

Training is key to any industry and most of the policy recommendations listed above revolve around making it easier for individuals to receive training prior to entering the craft. In a report developed by Bigelow et al [11], training was found to be a reason which current craft workers chose the construction field as a career and why they have continued to work in the construction industry. The availability of training received the most positive response out of all factors which attracted them to workforce in the first place, even outscoring salary. The results also showed that $78 \%$ of electricians stated that provided training is a factor in them staying with the industry [11].

When it comes to attracting and retaining a workforce, there are many factors which apply and can vary greatly between crafts. Of the electrician respondents, $89 \%$ stated that an increase in wage would be a positive retention factor and 
Anoop Sattineni / Proceedings of the Creative Construction Conference (2019) 059

https://doi.org/10.3311/CCC2019-059

salary was one of the primary reasons for selecting the craft to begin with [11]. One of the more surprising statistics from the survey conducted by Bigelow et al [11] was the listing of the industry's image as a positive factor in what attracted them to the industry. This is contrary to most reports which list the industry's image as one of the causes for the labor shortage.

The literature review has provided some key statistics and reports which help to understand the current state of the labor shortage, what are the potential causes, and what the industry believes will help to bridge the gap. The main take away from the literature review is there is a disconnect between the root causes of the labor shortage and the steps the industry is taking to eliminate it. The construction industry must be thorough in developing new methods in attracting a younger and more diverse workforce as their inability to close the gap in the past continues to plague the industry today and will continue to affect the industry in the future.

\section{Methodology}

A mixed-method research strategy was adopted in the conduct of this research. The research methodology employed for this research report consists of first conducting a series of pilot interviews and analysing the information obtained to generate survey questions. The aim for this research is to provide verification of the electrical worker labor shortage in the Midwest region and share the methods electrical companies and organizations are using to attract individuals to their trade. It was surmised that qualitative data from semi-structured interviews would provide a broad understanding of sentiments from industry professionals. The conclusions from the interview data will provide the basis for an industry wide survey to confirm / refine the findings.

\section{Results}

As stated in the methodology chapter, a series of pilot interviews were conducted to aid in developing a better survey. The interview was built from information about the skilled labor shortage from the literature review and was geared towards electrical union contractors. Content analysis of the transcribed interview data resulted in six major themes.

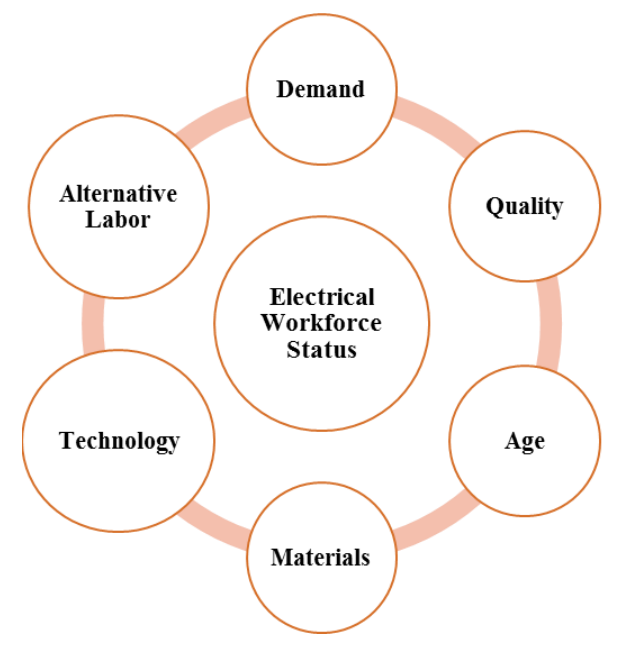

Fig. 2. Themes from Content Analysis of Pilot Interviews

\section{- Demand}

The first theme arose from the responses to several questions asked during the interview. The individuals whose primary work is in the metro east, Illinois side of Mississippi river, stated there is a declining market, but acknowledged that it is higher in others. The response obtained from a Missouri electrical contractor stated the demand is "rapidly increasing". These two varying opinions of the electrical workforce demand are vastly different even though their 
Anoop Sattineni / Proceedings of the Creative Construction Conference (2019) 059

https://doi.org/10.3311/CCC2019-059

jurisdictions are only separated by state lines. The cause of this difference was stated to be "Illinois politics and just the current state of the Illinois economy" by one interviewee while the other pointed out that significant amount of work in the metro east comes from industry. This is also why the demand for electrical workers quickly changes. One interviewee referred to the industry as "volatile" and of a "cyclical" nature. This relates back to information discovered during the literature as a component which dissuades individuals from joining the industry in the first place.

- Quality

Quality was another theme which surfaced from the content analysis. Here, the interviewees revealed that apprentices need to be more skilled due to changes in the industry, but on average they cared less about quality. The lesser quality results from trying to do the work fast and get it done instead of ensuring the work is completed correctly. This presents a serious issue for the industry and contractors alike as poor-quality leads to necessary re-work which in turn affects the profitability of the contractor. The older generation took great pride in their work and there is hope the newer generation will "grow into the skill" thus higher quality will follow.

\section{- Age}

When referring to apprentices, the opinion varies between the interviews on whether they are getting older or younger. One interviewee stated that " 20 years ago, it seemed like we always interviewed and brought in guys that are in their early twenties. I see apprentices now, seem to be even older". While their opinions were inconsistent with the age of apprentices, they all stated that the average age of their electrical workforce was in their 40's. One interviewee even broke their labor force down into the following statistics, "we have $27 \%$ baby boomers, $32 \%$ gen X, 39\% millennial generation and then now we're even coming into gen $Z$ at about $2 \%$ ". These statistics and average ages are in line with the national statistics for the electrical workforce as provided in the literature review.

- Materials and Technology

The next two themes discovered during the content analysis were materials and technology. These are grouped together as they go hand and hand in helping to create a more efficient workforce. Contractors can order materials from suppliers in a fashion called kitting in which every component for a room or job are packaged in one box which reduces the time a skilled individual spend rounding up the necessary materials for a specific project. Suppliers have improved the coatings on conduit to make it easier to pull without the need of adding soap. Technology has also led to new work for the electrical industry. As one interviewee stated, "there are smart tools now that the count crimps and have the right pressure for different things that are logging, spitting out logs automatically for the number of times that something was torqued and even locational things". All of this has helped the electrical industry to become more efficient and overcome potential shortfalls of a skilled labor force.

\section{- Alternative Labor}

The last theme developed from the content analysis was the use of alternative labor. Each interviewee discussed using less skilled labor to perform certain duties associated with the electrical craft. Improvements in technology and materials has helped spurred this as some tasks have been simplified such as one interviewee stated, "It's as simple as even wire, you think how can you improve wire? It's a simple product now they make it in colour. They're making it red, blue, so you don't have to think about what phase each one is when you pull it in". This allows contractors to use a less skilled workforce which in turn frees up some of the skilled workforce to complete more complicated task. As with any company, electrical contractors are always looking for efficiencies and developing a competitive advantage over other contractors.

\subsection{Survey Design}

The survey was designed with the aid of information obtained about the skilled labor workforce form the pilot interviews conducted previously. A total of 21 questions were posed to participants along with an ability to post 
Anoop Sattineni / Proceedings of the Creative Construction Conference (2019) 059

https://doi.org/10.3311/CCC2019-059

comments for each question. Some open-ended questions also posed to participants, thus allowing them to propose ideas beyond the questions asked.

\subsection{Survey Results}

To ensure the responses were being generated by personnel within the company who have direct ties to the electrical workforce, the first question sought demographical information about participant's role within the company. The results from this question were positive as $25 \%$ of the respondents were the owners of their respective companies, $25 \%$ were the company president, $25 \%$ were either vice president or company CEO, $17 \%$ were project managers, and $8 \%$ were corporate secretaries. Participants were asked about company and as seen in Figure 3, 67\% of the responses were received from companies with 50 or less employees. While the remaining $33 \%$ employed 51 or more. Continuing with developing an understanding of the company, respondents were asked about the type of electrical work the contractor typically worked on. For this question $92 \%$ of respondents worked on commercial contracts. $41 \%$ of the respondents selected other and specified project types such as cell towers, electrical signs, healthcare, telecommunication, and renewable energy. The results from the survey are found below in Figure 4.
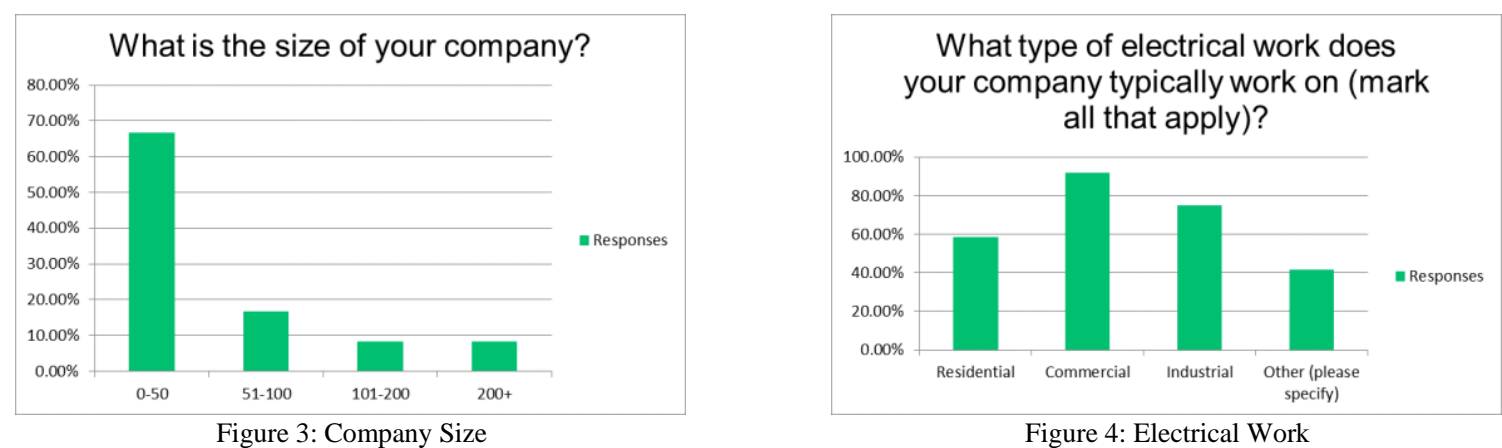

To make sure the survey was being responded to by electrical companies in the Midwest, the next question aimed to identify which regions of the United States the company does work. This resulted in a $100 \%$ success rate of companies working in the Midwest with a few of the companies also performing work in other regions as seen in Figure 5.

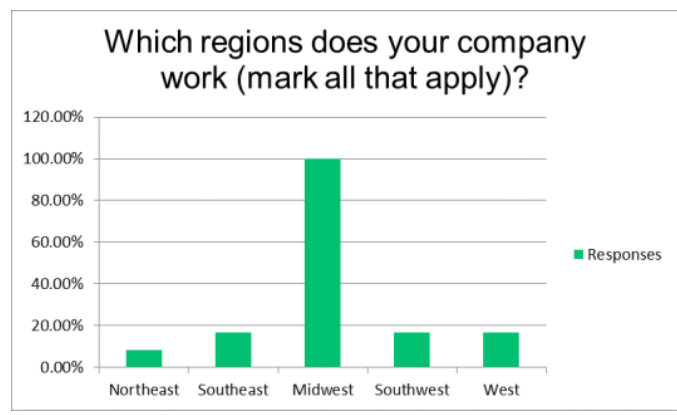

Figure 5: Regions

Participants were asked about the status of the electrical workforce is in the Midwest. Almost $60 \%$ of the respondents feel the current demand for their services is normal while $33 \%$ feel the current demand is lower than normal as seen in Figure 6. Additional comments received from this question noted the cyclical nature of the industry and that work was busier than normal over the last year, but the contractor is currently experiencing a slight slowdown. They also made mention that the type of work which they are involved in is more diverse than it was in the past. The next question requested that the respondents consider the future and forecast what they believe will be the change in demand over the next year. Here, $42 \%$ of respondents believed the demand will increase as seen in Figure 7. Another $25 \%$ responded the demand will decrease and the remaining $33 \%$ believe it will remain the same. 
Anoop Sattineni / Proceedings of the Creative Construction Conference (2019) 059

https://doi.org/10.3311/CCC2019-059

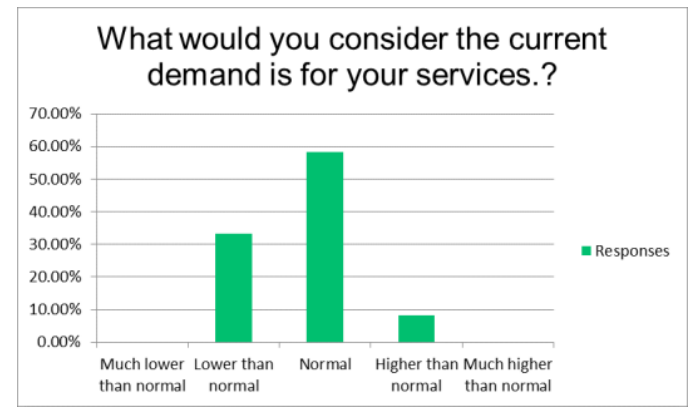

Figure 6: Demand

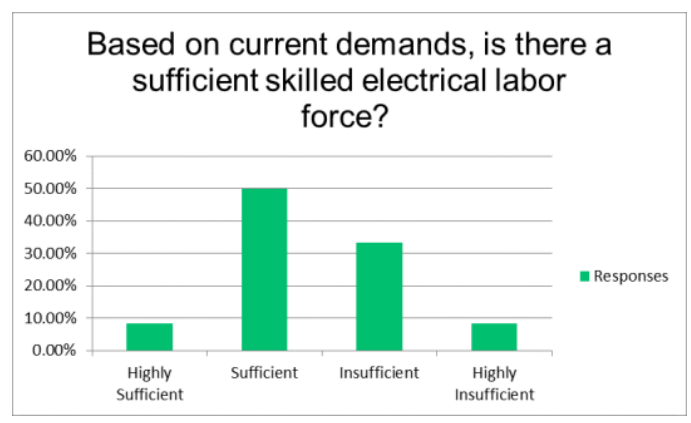

Figure 8: Sufficient Labor Force

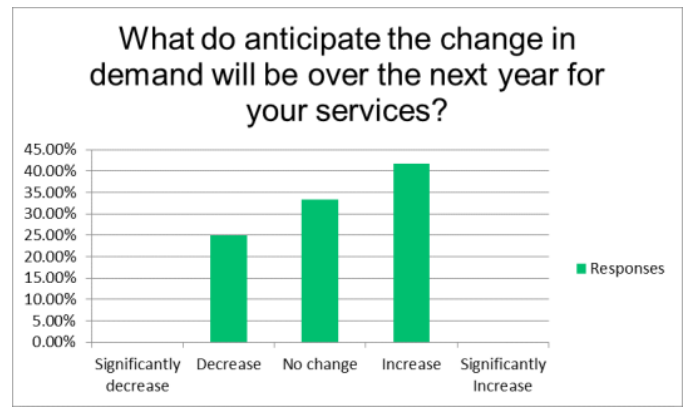

Figure 7: Change in Demand

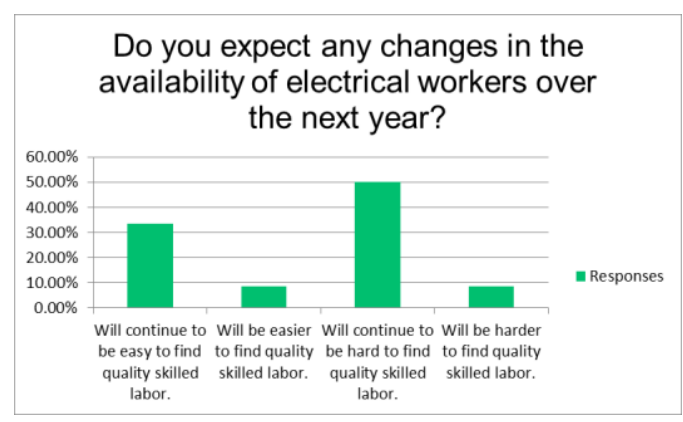

Figure 9: Change in Availability

Participants were asked if contractors consider the skilled electrical workforce enough regarding the current demand. The results revealed $58 \%$ of respondents feel there is enough or highly sufficient workforce while the other $42 \%$ feel it is lacking as seen in Figure 8. One comment received states, "The downturn from 2008-2012 created a gap. Less apprentices entered the trade. Many tradespeople took maintenance positions.". This belief is consistent with what was discovered during the literature review. Skilled workers lost their jobs during the recession and didn't return when the jobs came back. The next question received a similar distribution of responses when asked if they believed there would be any changes in the availability of electrical workers in the next year. 58\% of respondents believe it will continue to be hard or even become harder to find these skilled workers while the other $42 \%$ believe it will be easier, as shown in Figure 9. Contractors provided additional comments to this question which relate to similar themes discovered during the interview portion of the research. While another gives credit to technology for reducing the amount of manpower required to complete projects.

The next question aimed to see if contractors were satisfied with the skill set of electrical apprentices. While $42 \%$ of the respondents stated they are neutral on this subject, $33 \%$ were dissatisfied and the remaining $25 \%$ were very satisfied as shown in Figure 10. Participants were asked contractors to rate the overall quality of new electrical skilled labor in their region. The respondents replied with $75 \%$ average or above average, while the other $25 \%$ felt the quality was below average, as shown in Figure 11.

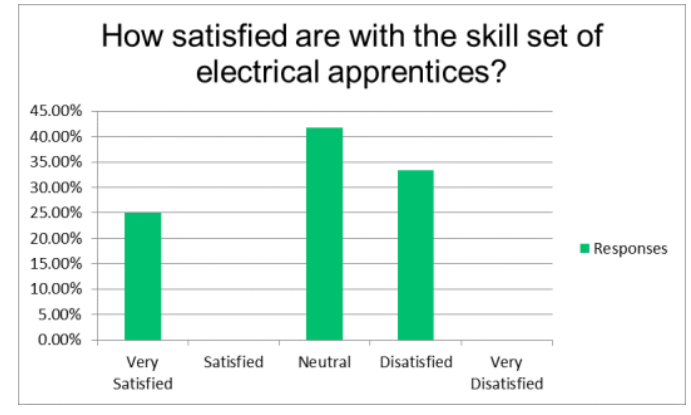

Figure 10: Electrical Apprentice Satisfaction

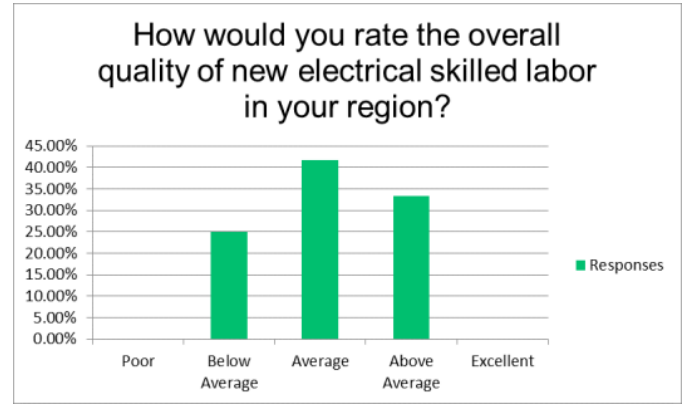

Figure 11: Rating of New Skilled Labor 
Anoop Sattineni / Proceedings of the Creative Construction Conference (2019) 059 https://doi.org/10.3311/CCC2019-059

The next question asked contractors to provide ways which technology has improved the electrical industry. While most of the respondents noted an improvement in materials, equipment, plans and training, nearly $17 \%$ stated that they have seen no noticeable improvement as seen in Figure 12. One respondent offered the following examples of how technology has helped to improve the industry, "Prefabrication and modularization allows us to build earlier and in better environments. Layout is twice as fast with robotics, wire pulls require 2 men not 6, iPads streamline info and collaboration". This response offers a few ways in which efficiencies have been obtained by improvements to products and methods made possible by advances in technology. Participants were asked to weigh in on if there have been any changes in workforce efficiencies over the past 5 years. Based on the previous answers, it seems like it would be a safe assumption to say yes, however only $25 \%$ of respondents feel the workforce efficiency has improved. Most of the respondents felt neutral on this topic while $17 \%$ feel efficiencies have declined. The results from the question can be found in Figure 13.

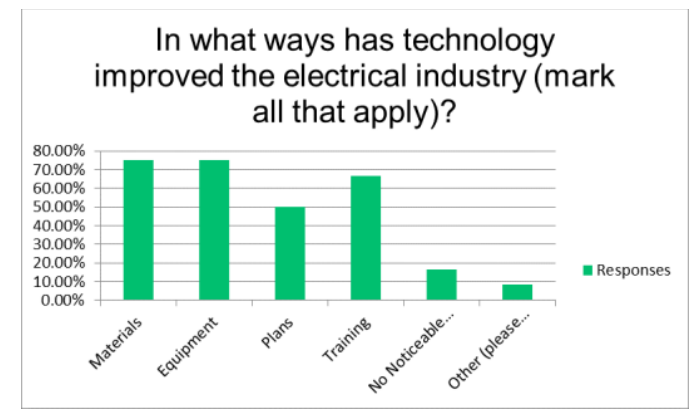

Figure 12: Technology Improvement

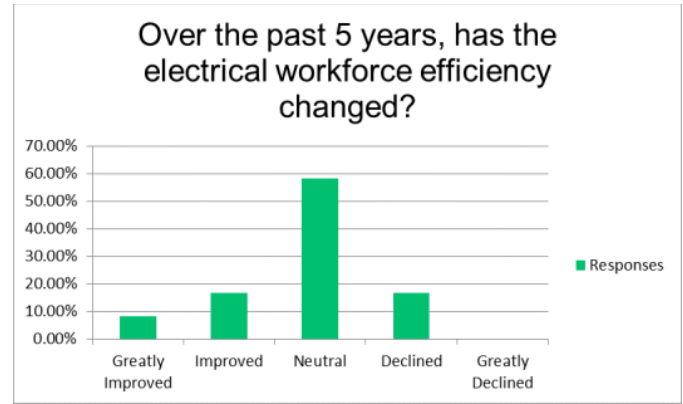

Figure 13: Workforce Efficiency

Respondents were asked to provide methods that they have used to increase efficiency on electrical projects. Of the results received, $25 \%$ stated they used prefabrication while $17 \%$ noted better tools, communication, and modelling software (BIM) to increase efficiency.

Due to all the attention given to the number of individuals due to retire in other skilled trades, participants were asked about the topic. Of the responses received, $67 \%$ stated they are slightly concerned to highly concerned about this topic while $33 \%$ have no concerns as seen in 14 . One contractor commented, "There are skill sets that will be lost as the next generation has different experience i.e. conduit bending - younger generation has only received prefabricated bent conduit, limited hands on bending". While the results show many contractors are concerned about the number of electricians due to retire, the responses were split evenly when asked if they are concerned the industry will not be able to recruit enough workers to replace those who do retire as seen in Figure15. One respondent noted, "Industry still structured for 100-man projects that now only require 60". This brings some light as to why some contractors are not concerned with the heavy loss of retired workers.

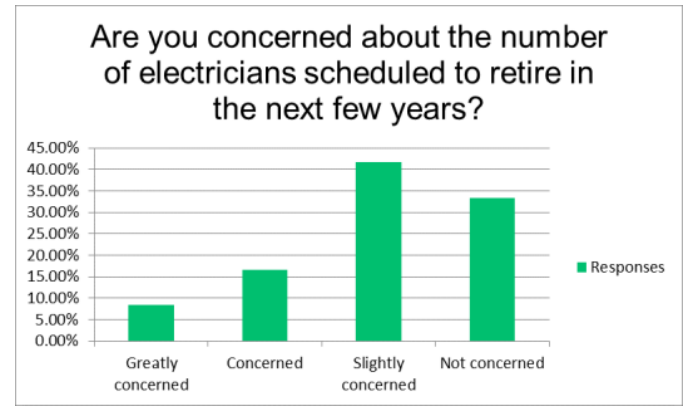

Figure 14: Retirement Concern

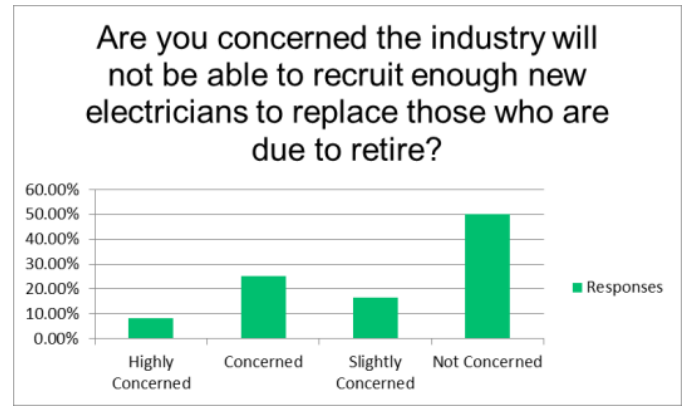

Figure 15: Replacement Concern

Participants were asked if they have found it difficult to retain electrical workers. Here, $75 \%$ of the respondents are neutral on the topic as many of them feel it is the union's responsibility to provide a workforce. The union also limits 
Anoop Sattineni / Proceedings of the Creative Construction Conference (2019) 059 https://doi.org/10.3311/CCC2019-059

what contractors can and cannot do to incentivize and attract union electricians to their company, as shown in Figure 16. The following question sought to discover what strategies contractors have used to retain workers. The results revealed $36 \%$ of the respondents used higher pay or bonuses to retain individuals while $45 \%$ provided a response which was not an option as seen in Figure 17. These responses included more work, improved culture, and since they are a union shop, the workers already have the best pay and benefits in the industry.

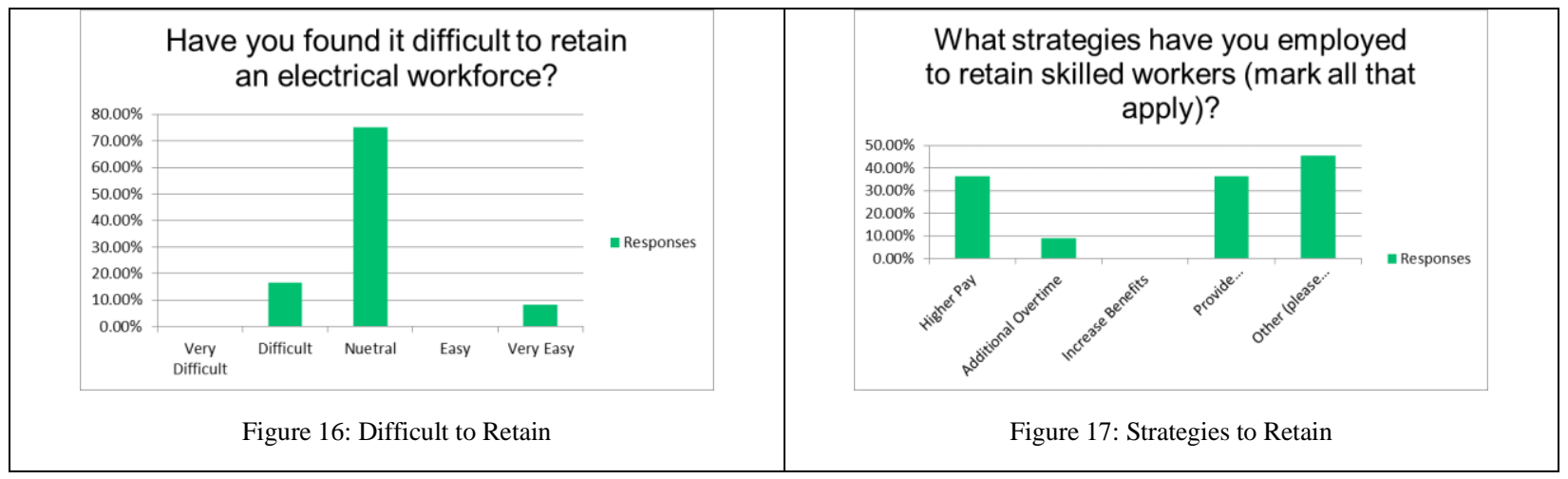

An open-ended question asked respondents to discuss what challenges they foresee retaining employees in the future. Of the responses received, $20 \%$ feel a lack of work or slowdowns in the industry and keeping the workforce happy and content will be their biggest challenge. Others noted that finding individuals with a good work ethic will prove to be difficult.

Participants were asked if they have used a less skilled worker to complete certain task on electrical projects and if they have or have not had issues. Of the responses received, $42 \%$ have not utilized while $33 \%$ have with success and the other 25\% have used with issues as seen in Figure 18. Additional comments received on this topic noted the additional planning and oversight which is needed to employ less skilled individuals as well as a loss in efficiency. The penultimate questions was asked to see if union contractors participate in recruiting activities or if they are completely reliant on the union to attract skilled workers. The results shown in Figure 19 show a near 50-50 split between those who occasionally or actively participate versus those who rarely or never participate.

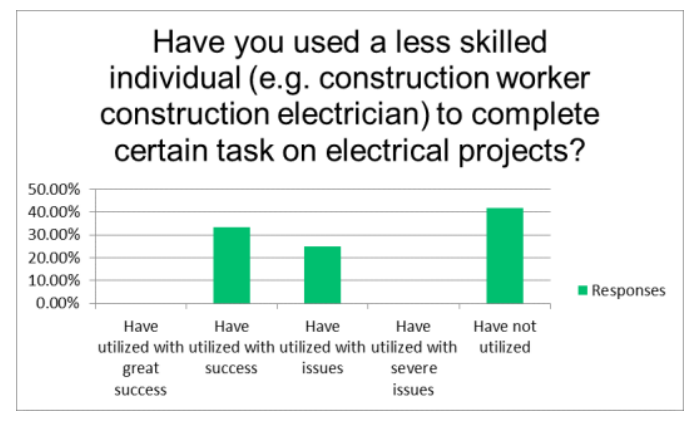

Figure 18: Less Skilled Labor Usage

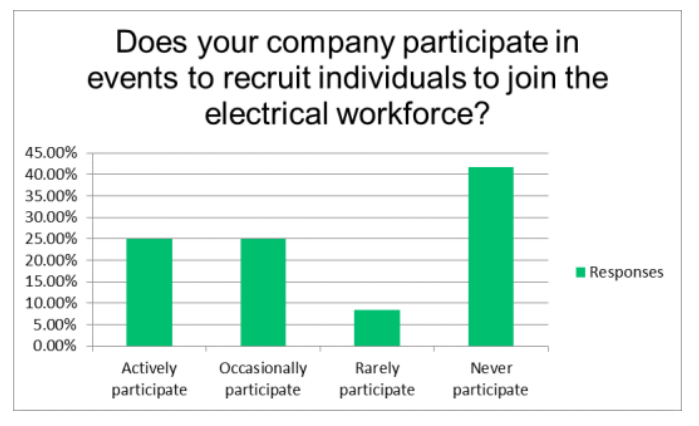

Figure 19: Recruitment

The final question was asked contractors to provide what they feel is the best way to recruit and develop the next generation of electrical workers. $27 \%$ of the responses received stated training as the best way to develop the next generation. One respondent noted, "The next generation needs to become mature and understand they must work to be retained by the company. The next generation does not understand "hard work" and assumes the position will come easy and that education, on their part, is a must". The words which the respondent has quoted, "hard work" is key to attracting individuals to the construction industry. It was discovered during the literature review that many people of the younger generation are afraid of hard work and working with their hands. This is a generational issue where older generations functioned off a "live to work" mentality and the newer generations follow a "work to live" mentality. Also affecting the younger generation is the plethora of opportunities which weren't available to older generations thus 
Anoop Sattineni / Proceedings of the Creative Construction Conference (2019) 059

https://doi.org/10.3311/CCC2019-059

affording them the ability to be less concerned about losing a job as other jobs may become available. Another respondent provided, "Definitive career path to journeyman wireman - current entry programs have ambiguous future. Work hard to resurrect the pride of being a trained craftsman. STEM programs in high schools, much of an electrician's responsibility is based upon math, science, and cutting-edge technology. Change recruiting message realization that a 4-year degree isn't for everyone, in lieu of borrowing $\$ 40 \mathrm{k}$ a year for four years to get a $\$ 40 \mathrm{k}$ a year job (if you're lucky), you can make $\$ 40 \mathrm{k}$ a year for four years and become a tradesman/woman making \$75k a year with great benefits". This is a great selling point for the union and electrical industry and getting the word out would be an excellent way to attract a younger generation.

\section{Conclusions and Recommendations}

The research conducted captured the current state of the Union electrical workforce which is just a snapshot in time. While the research did not discover any new or different trends that sets the skilled electrical workforce apart from other skilled construction labor, it was discovered that the electrical skilled labor shortage seems to be less of an issue in the Midwest when compared to the construction industry in general. Unions have been able to provide enough workforce to meet the needs of contractors over the last few years and many journeyman electricians and apprentices are currently unemployed in the region. The cyclical nature of the construction industry is truly feast or famine and can change very quickly. A benefit of being a union contractor allows them to forego the worrying of retaining and attracting new workers to the electrical workforce as this is the Unions job. However, nearly $50 \%$ of respondents do have a concern about the current labor situation and what will happen soon when approximately $20 \%$ of the current workforce retires.

The research revealed a few ways in which contractors are making themselves less dependent on this skilled labor. The material suppliers have realized this and are making electrical components more installer friendly and can even kit all the necessary components for wiring a room in one box, so the skilled electrician does not need to waste time tracking down the materials. Another component in increasing effectiveness and efficiency are developments in new technology which will continue to play a big role in making the industry less dependent on skilled labor. One common response from the interviews and surveys resonates the idea that, at least in the electrical industry, the efficiencies gained will help to overcome the challenges faced in recruiting new workers and retaining those already in the industry.

Researching and comparing multiple regions at the same time could provide key information on where the labor shortages and surpluses are most prominent. The labor shortage appears to be a regionalized issue as not all areas in the country are experiencing the same construction boom. This can be attributed to multiple factors which would lend itself to another study. Another recommendation would be to conduct the same surveys at different times of the year and with different construction skilled labor workforces to determine if there is any correlation between the time of year and workforce demand. This would also be highly affected by region as in northern states, many contractors are unable to work year-round due to temperature and weather. Based on responses received during the data collection process, it would be interesting to complete additional research to determine if the efficiencies gained through technology, materials, and tools are enough to overcome the skilled labor shortage. This appears to be the industries current mechanism for coping with potential shortages now and in the future. The final recommendation revolves around data gathering. The primary source of data collection for the survey's included gathering emails of perspective contractor's and send a link to an established survey. This was thought to be the easiest and most effective way to reach out to a larger population over a short period of time. In the end, many contractors disregarded the emails and only a small number of responses were received. Recommendations for future research on these topics in which a large population is desired would be to team with a contractor organization or union leaders to help encourage a better response rate. 
Anoop Sattineni / Proceedings of the Creative Construction Conference (2019) 059

https://doi.org/10.3311/CCC2019-059

\section{References}

[1] 2017 Construction Outlook Survey Results National Results, n.d.

[2] Labor Shortage Squeezes Builders [WWW Document], 2017. . Dow Jones Newswires. URL http://www.foxbusiness.com/features/2017/05/06/labor-shortage-squeezes-builders.html (accessed 8.19.17).

[3] Labor Force Statistics from the Current Population Survey [WWW Document], 2017. . Bur. Labor Stat. URL https://www.bls.gov/cps/cpsaat18b.htm (accessed 9.17.17).

[4] Electricians [WWW Document], 2015. . Occup. Outlook Handb. URL https://www.bls.gov/ooh/construction-and-extraction/electricians.htm (accessed 9.23.17)

[5] Registered Apprenticeship National Results Fiscal Year (FY) 2016 [WWW Document], 2017. . U. S. Dep. Labor. URL https://www.doleta.gov/oa/data_statistics.cfm (accessed 9.17.17).

[6] Cataldo, L., 2015. Building for the Future - Addressing Construction Industry Workforce Issues. Construction Trends.

[7] Sullivan, J., Kibert, C., Fenner, A., Morque, S., 2017. Florida Construction Workforce Taskforce: Determining the causes of the current shortage of a trained construction industry workforce and the impacts on the recovery of the real estate market.

[8] Albattah, M.A., Goodrum, P.M., Taylor, T.R.B., 2015. Demographic influences on construction craft shortages in the U. S. and Canada. https://doi.org/10.14288/1.0076372

[9] Quint, R., 2017. NAHB: Young Adults \& the Construction Trades [WWW Document]. URL https://www.nahbclassic.org/generic.aspx?genericContentID=255983\&channelID=311 (accessed 9.22.17).

[10] An Agenda to Rebuild Our Infrastructure \& Our Craft Workforce, n.d.

[11] Bigelow, B.F., Zarate, V., Soto, J., Arenas, J., Perrenoud, A., 2017. Attracting and Retaining Tradespeople, an Evaluation of Influencers on Construction Workers in Two Different Trades in Texas. Int. J. Constr. Educ. Res. 0, 1-16. https://doi.org/10.1080/15578771.2017.1280103 